\section{P2-535 PROGRESS TOWARDS ERADICATION OF POLIOMYELITIS IN GHANA: A REVIEW OF EASTERN REGION- GHANA, 1997-2009}

doi:10.1136/jech.2011.142976m.62

${ }^{1,2} \mathrm{~J}$ Opare, ${ }^{* 1} \mathrm{C}$ Ohuabunwo, ${ }^{1,2} \mathrm{E}$ Afari, ${ }^{1,2} \mathrm{G}$ Bonsu, ${ }^{1,2} \mathrm{~S}$ Sackey, ${ }^{1} \mathrm{~F}$ Wurapa. ${ }^{1} \mathrm{G}$ hana Field Epidemiology and Laboratory Training Programme, School of Public Health, Legon, Accra, Greater Accra region, Ghana; ${ }^{2}$ Greater Accra Region, Ghana Health Service, Accra, Ghana

Background Poliomyelitis is a highly infectious viral disease transmitted feco-orally, mainly affecting children under 15 years old. One in 200 infections leads to irreversible paralysis and immunisation can prevent poliomyelitis. Acute Flaccid Paralysis (AFP) surveillance, is used to documents the presence or absence of wild polio-virus. An in-depth review of AFP data in the Eastern Region was undertaken to assess the progress towards interruption of polio-virus transmission and to identify opportunities for system improvement. Methods We conducted a secondary data analysis of AFP cases reported to the Regional Health Directorate from 1997 to July 2009. We reviewed records, calculated AFP surveillance performance indicators and described AFP-cases, surveillance indicators and polio vaccination by person, place and time.

Results Between 1999 and July 2009, of the 273 AFP-cases reported, one wild polio-virus was recorded. The non-polio AFP rate ranged from 0.12 to $3.94 / 100000$ and stool adequacy from $60 \%$ to $80 \%$. The prevalence of non-polio entero-viruses was $8.4 \%$. Thirty seven percent of the AFP-cases were males $<5$ years old. Most AFP-cases $38 / 273$ (14.0\%) occurred in October with Suhum District recording the highest $30 / 273(11.0 \%)$. The commonest site of paralysis was the right lower limb 85/273 (31.0\%) and asymmetric paralysis represented169/273 (62\%). Forty percent (109/273) of AFP-cases had three polio-vaccine doses. Completeness of data from case-based forms was however inadequate.

Conclusions The AFP surveillance indicators reflect consistent progress towards interruption of polio-virus transmission. However, the programme needs to improve on the completeness of case-based forms and stool quality. Surveillance officers have been re-trained on data management.

\section{P2-536 CO-OCCURRENCE OF ANXIETY AND DEPRESSION AMONG OLDER ADULTS IN LOW AND MIDDLE-INCOME COUNTRIES: FINDINGS FROM THE 10/66 STUDY}

doi:10.1136/jech.2011.142976m.63

\begin{abstract}
${ }^{1} \mathrm{M}$ Prina, ${ }^{*} \mathrm{C}$ Ferri, ${ }^{2,3} \mathrm{M}$ Guerra, ${ }^{1} \mathrm{C}$ Brayne, ${ }^{2} \mathrm{M}$ Prince. ${ }^{1}$ University of Cambridge, Cambridge, UK; ${ }^{2}$ Institute of Psychiatry, King's College London, London, UK; ${ }^{3}$ Universidad Peruana Cayetano Heredia, Lima, Peru
\end{abstract}

Background There is relative little information about the prevalence and risk factors of co-morbid anxiety and depression in later life. These disorders are often associated with worse response to treatment than either condition alone, and researching its epidemiology in diverse settings is vital to policy makers. We therefore investigated the co-occurrence of anxiety and depressive syndromes among older adults living in developing countries and measured the separate and joint effect of these two disorders on levels of associated disability.

Method The 10/66 study carried out cross-cultural surveys of all residents aged 65 or over $(n=15021)$ in 11 sites in seven countries (China, India, Cuba, Dominican Republic, Venezuela, Mexico and Peru). Anxiety was measured by using the Geriatric Mental State Examination (GMS) and the AGECAT diagnostic system. Depression was assessed according to ICD-10 and EURO-DEP criteria. Disability was measured by using the WHO-Disablement Assessment Scale Version II (WHODAS-II). Negative binomial regression models (ZINBs) were used to investigate the association between common mental disorders and disability.

Results Co-morbid anxiety and depression was high (range \%: 14.4-26.8) in the Latin American and Indian sites. Gender, socioeconomic status, urbanicity and physical co-morbidities were associated with the different co-morbid states. Having both disorders was linked to higher disability scores than having anxiety or depression alone.

Conclusions Given the close association of co-morbid anxiety and depression with disability, new policies to improve prevention, recognition and treatment will be needed to adapt to ageing populations and their mental health needs.

\section{P2-537 TRACKING PROGRESS TOWARDS ELIMINATION OF IODINE DEFICIENCY DISORDERS IN PUDUCHERRY (INDIA), A SCHOOL BASED STUDY}

doi:10.1136/jech.2011.142976m.64

${ }^{1} \mathrm{~A} J$ Purty, ${ }^{*}{ }^{1} \mathrm{P}$ Mahajan, ${ }^{1} \mathrm{Z}$ Singh, ${ }^{1,2} \mathrm{~A}$ Meenakshi, ${ }^{1} \mathrm{~N}$ Murugan, ${ }^{1} \mathrm{~J}$ Cherian, ${ }^{1} \mathrm{~A}$ Senthilvel, ${ }^{3} \mathrm{D}$ Gurumurthy. ${ }^{1}$ Pondicherry Institute of Medical Sciences, Pondicherry, India; ${ }^{2}$ Clinical Biochemistry PIMS, Pondicherry, India; ${ }^{3}$ Directorate of Health (Nutrition), Government of Puducherry, India

Background and Objectives Iodine deficiency disorders (IDDs) though largely preventable continue to be an important public health problem worldwide. IDDs have been reported from Puducherry and the surrounding States. We undertook this survey in all the four districts of the UT of Puducherry to study the prevalence of goitre in a sample of school children, to measure the level of iodine in salt samples and to determine the median urinary iodine concentration in a sample of these children so that the progress towards IDD elimination in the region can be assessed.

Methods In a cross-sectional study among 2581 school-going children in the age group of 6-12 years in the UT of Puducherry. A total of 30 clusters were selected by the PPS (Population proportion to size) method. The children were clinically examined for presence of goitre, urine samples were collected and salt samples from their kitchens were tested for iodine concentration.

Results The total goitre prevalence (TGP) was $27.5 \%$ (moderately endemic) among the children examined. The median urinary iodine concentration (MUI) was $142.9 \mu \mathrm{g} / \mathrm{l}$ (normal 100-199 $\mu \mathrm{g} / \mathrm{l}$ ). Only $7 \%$ of children (target $<20 \%$ ) showed low MUI $(<100 \mu \mathrm{g} / \mathrm{l})$. Iodine content was found to be adequate $(>15 \mathrm{ppm}$ ) in over $60 \%$ (target $>90 \%$ ) of the salt samples.

Interpretation and Conclusions Goitre is still an important public health problem in Puducherry and as it's important for the mental development of children, the various operational factors need to be identified to strengthen the NIDDCP and improve the consumption of iodised salt.

\section{P2-538 USING THE CES-D SCALE IN A LARGE COHORT AND DEALING WITH MISSING DATA: APPLICATION TO THE FRENCH E3N COHORT}

doi:10.1136/jech.2011.142976m.65

${ }^{1,2} \mathrm{~N}$ Resseguier, ${ }^{*} \mathrm{H}$ Verdoux, ${ }^{4} \mathrm{~F}$ Clavel-Chapelon, ${ }^{1} \mathrm{X}$ Paoletti. ${ }^{1}$ Biostatistics Department, Institut Curie, Paris, France; ${ }^{2}$ LERTIM, EA 3283, Aix-Marseille University, Faculty of Medicine, Marseille, France; ${ }^{3}$ Inserm U657, Bordeaux, France; ${ }^{4}$ Inserm U1018, Institut Gustave Roussy, Villejuif, France

Introduction The CES-D scale is commonly used to assess depressive symptoms (DS) in large population-based studies. Missing data (MD) in one or several of the 20 items of the scale are frequent and may create biases. Reasons for not completing items and impact on the estimation the prevalence of DS under various hypotheses are explored. 